\title{
Detection of a REE-rich, F- and P-bearing fluid component in superdeep diamonds from Kankan (Guinea).
}

\author{
Frank E. Brenker ${ }^{1}$, Laszlo Vincze ${ }^{2}$, Bart Vekemans ${ }^{2}$, Anja Szymanski ${ }^{1}$, Wout De Nolf ${ }^{3}$, \\ Koen Janssens ${ }^{3}$, Thomas Stachel ${ }^{4}$, Jeff Harris ${ }^{1,5}$ \\ ${ }^{I}$ Geoscience Institute / Mineralogy, Johann-Wolfgang-Goethe University, Frankfurt/Main, Germany, ${ }^{2}$ Department \\ of Analytical chemistry, Ghent University, Gent, Belgium, ${ }^{3}$ Centre for Micro- and Trace Analysis - Department of \\ Chemistry, Antwerp University, Antwerp, Belgium, ${ }^{4}$ Department of Earth and Atmospheric Sciences, University of \\ Alberta, Edmonton, Alberta, T6G 2E3, Canada, ${ }^{5}$ Division of Earth Sciences, University of Glasgow, Glasgow G12 \\ 8QQ, Scotland,UK (f.brenker@em.uni-frankfurt.de)
}

Synchrotron based confocal X-ray fluorescence analyses were performed at the ESRF (European Synchroton Radiation Facility, Grenoble) on a set of Kankan diamonds (Vekemans et al, 2004, Vincze et al., 2004). Of special interest was a large Kankan diamond containing many Ca-Si-O rich inclusions (KK200). Investigations applying Raman spectroscopy yield $\mathrm{CaSiO}_{3}$ walstromite, $\mathrm{CaSi}_{2} \mathrm{O}_{5}$ titanite and larnite (beta$\mathrm{Ca}_{2} \mathrm{SiO}_{4}$ ) as inclusion paragenesis. The varying proportions of the respected phases indicate a depth of origin within the two phase field of larnite $+\mathrm{CaSi}_{2} \mathrm{O}_{5}$ titanite between 300 and 360km (Brenker et al., 2005).

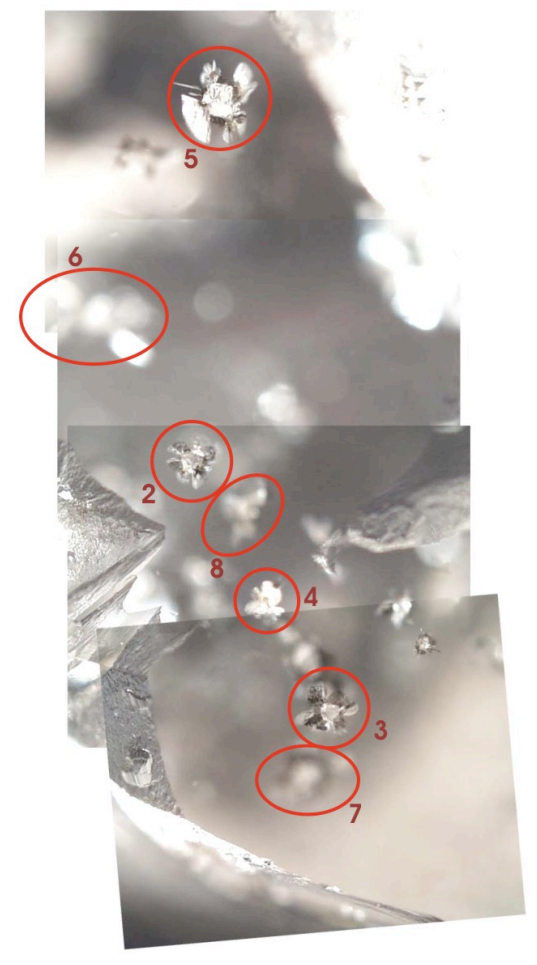

Fig. 1 Inclusions in diamond KK200. No. \#3 is studied in greater detail in this work

Detailed trace element tomography of several cubooctahedral inclusions and their surrounding narrow fractures show that contrary to our expectation the fractures are actually filled with material. The fracture filling shows close similarities in trace element composition to the mineral inclusions, in addition to being generally enriched in REE. The former existence of a fluid or melt is required to transport material into these elongated fractures. This interpretation is further confirmed by X-ray diffraction measurements which indicate the presence of florencite and La-cerite crystals within the fracture fills.

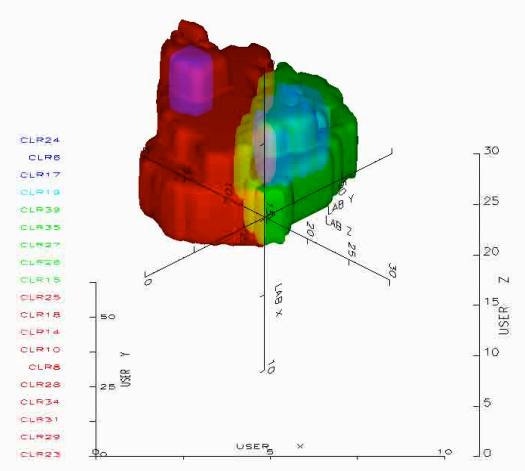

Fig. 2 Trace element distribution of a polyphase inclusion (KK200\#3). The detected phases are walstromite, larnite and othe $\mathrm{Ca}-\mathrm{Si}$-Orich mineral phases

The most likely interpretation is the entrapment of a volatile component during diamond growth, probably dissolved at high pressure within the solid inclusion phases. During uplift of the diamonds and associated pressure release this volatile content is expelled from the solid inclusion as a fluid and penetrates into the newly forming fractures. 


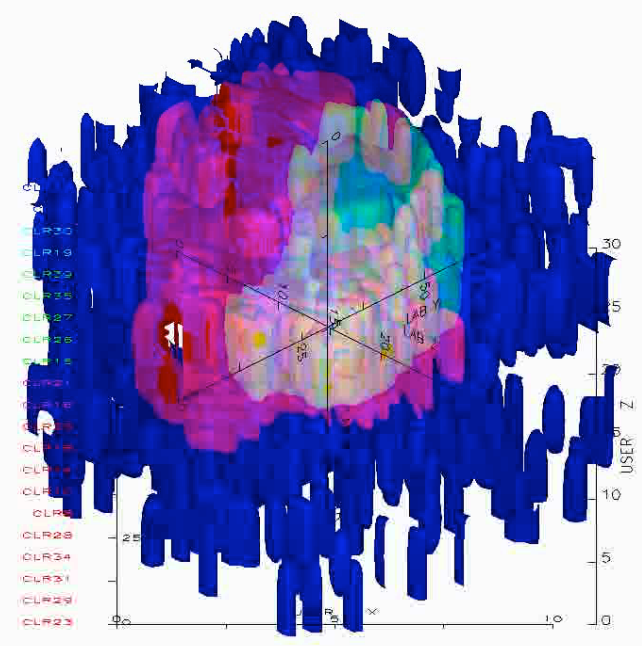

Fig. 3 Trace element distribution around inclusion KK200\#3.

Brenker, F.E., Vincze, L., Vekemans, B., Nasdala, L., Stachel, T., Vollmer, C., Kersten, M., Somogyi, A., Adams, F., Joswig, W. \& Harris, J.W., 2005, Detection of a Ca-rich lithology in the Earth's deep $(>300 \mathrm{~km})$ convecting mantle, Earth and Planetary Science Letters 236, 579-587.

Vekemans, B., Vincze, L., Brenker, F.E., Adams, F., 2004. Processing of three-dimensional microscopic X-ray fluorescence data, Journal of Analytical Atomic Spectrometry 19, 1302-1308.

Vincze, L., Vekemans, B., Brenker F.E., Falkenberg, G., Rickers K., Somogyi, A., Kersten, M. \& Adams, F., 2004. Three-dimensional trace element analysis by confocal X-ray microfluorescence imaging, Analytical Chemistry 76, 6786-6791. 